\title{
Magnetic storm free ULF analysis in relation with earthquakes in Taiwan
}

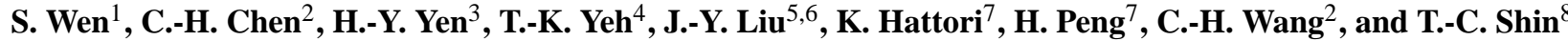 \\ ${ }^{1}$ Institute of Seismology, National Chung Cheng University, Chiayi 621, Taiwan \\ ${ }^{2}$ Institute of Earth Sciences, Academia Sinica, Taipei 115, Taiwan \\ ${ }^{3}$ Institute of Geophysics, National Central University, Jhongli 320, Taiwan \\ ${ }^{4}$ Department of Real Estate and Built Environment, National Taipei University, New Taipei City 237, Taiwan \\ ${ }^{5}$ Institute of Space Science, National Central University, Jhongli 320, Taiwan \\ ${ }^{6}$ Center for Space and Remote Sensing Research, National Central University, Jhongli 320, Taiwan \\ ${ }^{7}$ Graduate School of Science, Chiba University, Inage, Chiba 263-8522, Japan \\ ${ }^{8}$ Central Weather Bureau, Taipei 10048, Taiwan
}

Correspondence to: C.-H. Chen (nononochchen@gmail.com)

Received: 25 October 2011 - Revised: 2 April 2012 - Accepted: 3 April 2012 - Published: 25 May 2012

\begin{abstract}
Despite early optimism, pre-earthquake anomalous phenomena can be determined by using enhanced amplitude at the ultra-low-frequency range from geomagnetic data via the Fourier transform. In reality, accuracy of the enhanced amplitude in relation to earthquakes (deduced from time-varied geomagnetic data) would be damaged by magnetic storms and/or other unwanted influences resulting from solar activity and/or variations in the ionosphere, respectively. We substitute values of the cross correlation between amplitudes, summarized from the earthquake-related (0.1$0.01 \mathrm{~Hz})$ and the comparable $(0.01-0.001 \mathrm{~Hz})$ frequency bands, for isolated amplitude enhancements as indexes of determination associated with seismo-magnetic anomalies to mitigate disturbance caused by magnetic storms. A station located about $300 \mathrm{~km}$ away from the others is also taken into account to further examine whether changes of the cross correlation values are caused by seismo-magnetic anomalies limited within local regions or not. Analytical results show that the values suddenly decrease near epicenters a few days before and after $67 \%(=6 / 9)$ of earthquakes $(M>=5)$ in Taiwan between September 2010 and March 2011. Seismomagnetic signals determined by using the values of cross correlation methods partially improve results yielded from the Fourier transform alone and provide advantageous information of earthquake locations.
\end{abstract}

\section{Introduction}

Seismo-magnetic phenomena are observed within a wide frequency range from DC (direct current) to VLF (very low frequencies), and have been reported in many studies (e.g. Hayakawa and Fujinawa, 1994; Hayakawa, 1999; Hayakawa and Molchanov, 2002; Molchanov and Hayakawa, 2008, Rozhnoi et al., 2009). Fraser-Smith et al. (1990) observed that the amplitude of the geomagnetic field at the ultra-lowfrequency (ULF) band of $0.05-0.2 \mathrm{~Hz}$ suddenly increased few hours prior to the $M=7.1$ Loma Prieta earthquake. Based on convincing evidence from that amplitude, the ULF frequency band is repeatedly enhanced and consistently identified prior to other major earthquakes (Bernardi et al., 1991; Molchanov et al., 1992; Kopytenko et al., 1993; Merzer and Klemperer 1997; Kawate et al., 1998; Hayakawa et al., 1996, 2000; Gotoh et al., 2002; Hattori et al., 2002, 2004a, 2004b; Hattori, 2004); geomagnetic amplitude increases within the ULF range in response to seismo-magnetic anomalies, which are generally considered as having great potential for earthquake monitoring.

Taiwan is located in a high seismicity area at the western edge of the Pacific Ocean and at the boundary of the Philippine Sea Plate and Eurasian Plate (Ho, 1988). To study seismo-magnetic anomalies, a network of geomagnetic stations has been established in Taiwan since 1988 (Yen et al., 2004). The network is currently comprised of 11 stations 
Table 1. Locations of 11 geomagnetic stations in Taiwan.

\begin{tabular}{llll}
\hline Stations & Code & Latitude $\left({ }^{\circ} \mathrm{N}\right)$ & Longitude $\left({ }^{\circ} \mathrm{E}\right)$ \\
\hline Neicheng & NC & 24.7181 & 121.6681 \\
Yeheng & YH & 24.671 & 121.3671 \\
Liyutan & LY & 24.3467 & 120.7675 \\
Hualien & HL & 24.0678 & 121.6006 \\
Shuanlung & SL & 23.7902 & 120.9441 \\
Yuli & YL & 23.3506 & 121.2856 \\
Tsengwen & TW & 23.2514 & 120.5167 \\
Taitung & TT & 22.8019 & 121.0519 \\
Pingtung & PT & 22.7035 & 120.6496 \\
Hengchun & HC & 21.935 & 120.8008 \\
Kinmen & KM & 24.4471 & 118.4164 \\
\hline
\end{tabular}

(Table 1). Locations of the 11 stations were chosen carefully away from populated areas to diminish interference from visible iron objects, power lines and artificial noise (Yen et al., 2004). Identical proton magnetometers with the sensitivity of $0.1 \mathrm{nT}$ are equipped at these stations and routinely monitor variations of geomagnetic total intensity field using $1 \mathrm{~Hz}$ sampling rate (Chen et al., 2009a). Chen et al. (2009a) prudently examined data quality of the 11 stations by the Chapman-Miller method (Chapman and Miller, 1940), and found that tiny signals caused by the magnetic lunar effects can be observed. Although these total intensity data retrieved from this network are difficult to be used to observe changes in direction of magnetic fields, good quality and a long observation period (from 1988 to now) of data are sufficient to be utilized in most geomagnetic studies (Chen et al., 2004, 2009a, 2010, 2011a; Liu et al., 2006; Yen et al., 2004, 2009).

The $M=9.0$ Tohoku earthquake $\left(142.38^{\circ} \mathrm{E}, 38.30^{\circ} \mathrm{N}\right)$ occurred on 11 March 2011, striking northern and eastern Japan as the most destructive earthquake thus far in the 21 st century. To examine whether influence of seismomagnetic anomalies excited by the Tohoku earthquake can reach the geomagnetic field in Taiwan or not, geomagnetic data recorded at the aforementioned 11 stations are examined. We found that the amplitude at earthquake-related frequency band (i.e. $0.01-0.1 \mathrm{~Hz}$ ) was enhanced during the Tohoku earthquake. However, when the Dst (disturbance storm time) index is taken into account, a magnetic storm, which possibly excites amplitude increase at the earthquakerelated frequency band, also happened during the Tohoku earthquake.

In this study, geomagnetic total intensity data recorded at 8 stations (Neicheng (NC), Yeheng (YH), Hualien (HL), Shuanlung (SL), Tsengwen (TW), Taitung (TT) and Hengchun (HC) in Taiwan, as well as the Kinmen (KM) station located about $300 \mathrm{~km}$ away from the other measurements) from 1 September 2010 to 17 March 2011 are used to compute amplitude by using the fast Fourier transform (FFT). Note that geomagnetic data at Liyutan (LY), Yuli (YL) and Pingtung (PT) are eliminated from the fol-

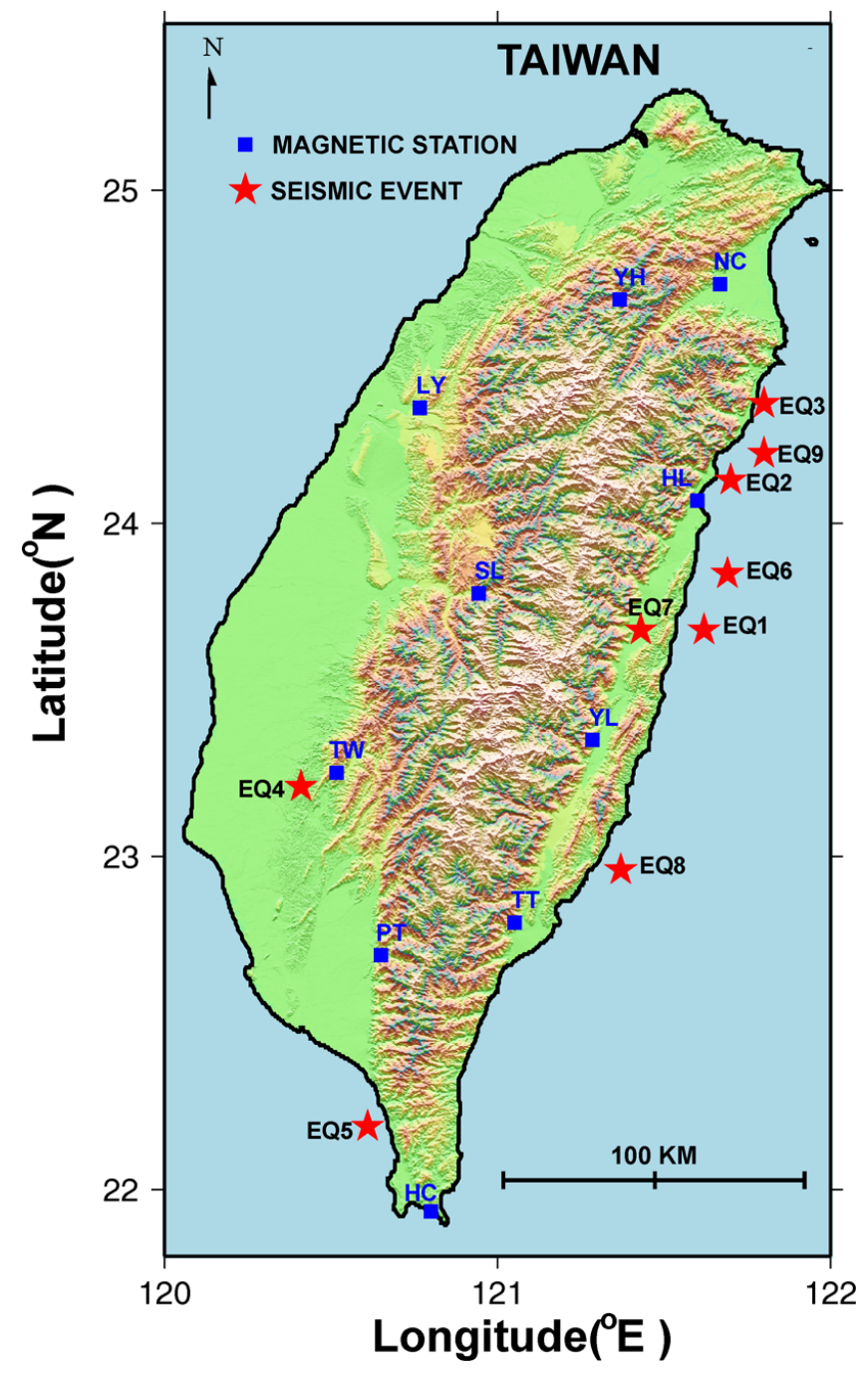

Fig. 1. The topographic map of Taiwan. The red stars denote the epicenters of 9 studied earthquakes. Blue squares show locations of the geomagnetic stations in Taiwan.

lowing analysis because discontinuity data yielded by gaps would damage analytical results. Derived amplitudes are examined along with 9 earthquakes with $M \geq 5.0$ (Table 2) that occurred near or within Taiwan (retrieved from the earthquake catalog of the Central Weather Bureau, Taiwan (http: //www.cwb.gov.tw)). Amplitudes at the earthquake-related and the other frequency bands are compared by using the cross correlation to clarify amplitude increase in response to either earthquakes or magnetic storms.

\section{Preliminary investigations}

Geomagnetic fields are mainly affected by variations in the ionosphere and magnetosphere, as well as induction fields generated by resistive structures in the subsurface (Chapman and Bartels, 1940). It is well known that solar activity 
Table 2. Earthquakes retrieved from the catalog of Central Weather Bureau (http://www.cwb.gov.tw) in relation to this study.

\begin{tabular}{lrrrrrrrr}
\hline & Year & Month & Day & Long $\left({ }^{\circ} \mathrm{E}\right)$ & Lat $\left({ }^{\circ} \mathrm{N}\right)$ & Depth $(\mathrm{km})$ & Magnitude & $\begin{array}{r}\text { Days after } \\
\text { Sep } 2010\end{array}$ \\
\hline EQ1 & 2010 & 9 & 20 & 121.62 & 23.68 & 36.2 & 5.1 & 20 \\
EQ2 & 2010 & 9 & 29 & 121.7 & 24.13 & 9 & 5 & 29 \\
EQ3 & 2010 & 10 & 3 & 121.8 & 24.36 & 19.4 & 5.1 & 33 \\
EQ4 & 2010 & 11 & 8 & 120.41 & 23.21 & 17.5 & 5.2 & 69 \\
EQ5 & 2010 & 11 & 12 & 120.61 & 22.19 & 38 & 5.3 & 73 \\
EQ6 & 2010 & 11 & 21 & 121.69 & 23.85 & 46.9 & 6.1 & 82 \\
EQ7 & 2010 & 12 & 6 & 121.43 & 23.68 & 24.8 & 5.2 & 97 \\
EQ8 & 2010 & 12 & 7 & 121.37 & 22.96 & 40.5 & 5.1 & 98 \\
EQ9 & 2011 & 2 & 1 & 121.8 & 24.21 & 18.3 & 5.5 & 154 \\
Tohoku & 2011 & 3 & 11 & 142.38 & 38.3 & 24 & 9 & 192 \\
\hline
\end{tabular}

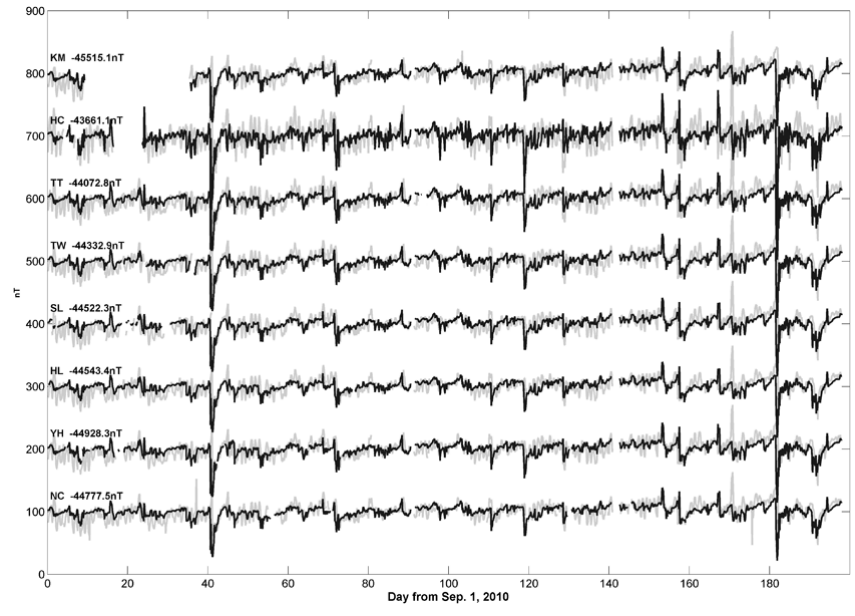

Fig. 2. Variations of geomagnetic field at 8 stations in Taiwan from 1 September 2010 to 17 March 2011. Shadow and black lines denote the variations of geomagnetic field on the day side (07:0015:00 LT) and the night side (19:00-03:00 LT). A number following the station code is a shift value from raw data.

intensely affects geomagnetic fields, resulting in geomagnetic daily variations (Chapman and Bartels, 1940). To understand influence resulting from solar activity, geomagnetic data at the 8 studied stations are separated into the daytime (07:00-15:00 LT) and nighttime (19:00-03:00 LT) phases. Figure 2 shows variations of raw data of geomagnetic fields in Taiwan during the entire study period (i.e. from 1 September 2010 to 17 March 2011). Great fluctuations are observed from the daytime data when observation stations were on the day side. By contrast, variations of geomagnetic nighttime data are relatively smooth because effects of solar activity are reduced when observation stations were on the night side. It is worth mentioning that geomagnetic fields suddenly decrease and maintain 2-4 days due to magnetic storms on 41st, 72nd, 110th, 119th 157th, 167th, 171st, 181st and 191st days from the "starting" day (i.e. 1st day is 1 September 2010).
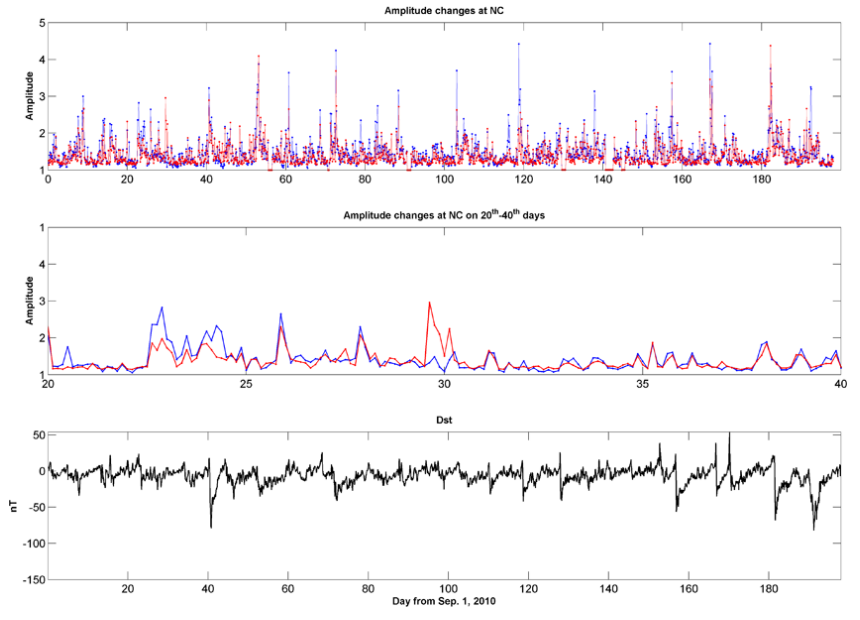

Fig. 3. First panel: variations of the ULF amplitudes observed from 1 Septemebr 2010 to 17 March 2011, at the NC station at two frequency bands, $0.01-0.001 \mathrm{~Hz}$ and $0.1-0.01 \mathrm{~Hz}$. Second panel: ULF variations observed during the period from 20 September 2010 to 10 Octtober 2010. Note that red and blue lines denote the processed amplitude at $0.01-0.1 \mathrm{~Hz}$ and $0.001-0.01 \mathrm{~Hz}$, respectively. Third panel: Dst parameter variation versus the investigated period (i.e. 1 September 2010 to 17 March 2011).

These magnetic storms provide a good opportunity to clarify factors of amplitude increase.

To avoid effects of solar activity, we apply to the nighttime observations a FFT temporal window of $3600 \mathrm{~s}$, with a step of $1 \mathrm{~h}$ at the earthquake-related frequency band of 0.01$0.1 \mathrm{~Hz}$. By contrast, we further process amplitude at a frequency band of $0.001-0.01 \mathrm{~Hz}$ via the same analytical hypothesis and take it as a reference. Figure 3 shows a good relationship between variations of the processed amplitude at the frequency bands of $0.01-0.1$ and $0.001-0.01 \mathrm{~Hz}$. The Dst parameter and the processed amplitudes show similar variations. This suggests that amplitude at the earthquakerelated frequency band of $0.01-0.1 \mathrm{~Hz}$ would be enhanced in relation to either earthquakes or magnetic storms. Thus, 

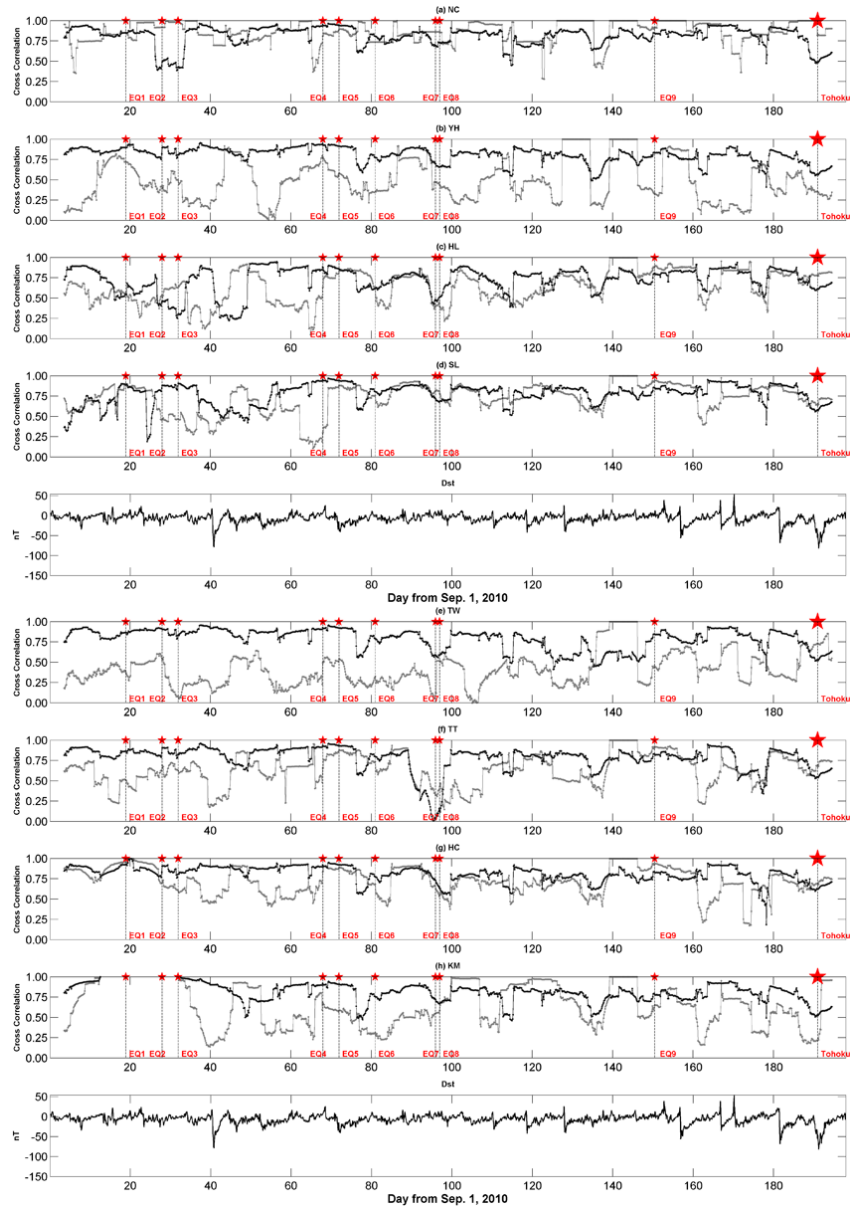

Fig. 4. The cross correlation values at the 8 stations and Dst from 1 September 2010 to 17 March 2011. Shadow and black lines denote the cross correlation values derived from the daytime and nighttime data.

determination of pre-earthquake anomalous phenomena depends on amplitude increase at the earthquake-related frequency band, which alone would take high risks. Therefore, enhanced amplitude resulting from magnetic storms should be removed first before it is used to compare with earthquakes.

\section{Methodology and data processing}

The combination of the two processed amplitudes allows us to find a different behavior. As shown in the middle panel of Fig. 3, a clear increase and decrease of amplitude are observed in the daytime interval between 29 and 31, respectively, at the band of $0.01-0.1 \mathrm{~Hz}$ and $0.001-0.01 \mathrm{~Hz}$. This time interval corresponds to the period of occurrence of EQ2 and EQ3. To further extract the discrepancy, we compute values of the cross correlation between the two processed amplitudes using a temporal moving window of 7-days with a 1-day step. Figure 4 shows the analytical results of cross cor-
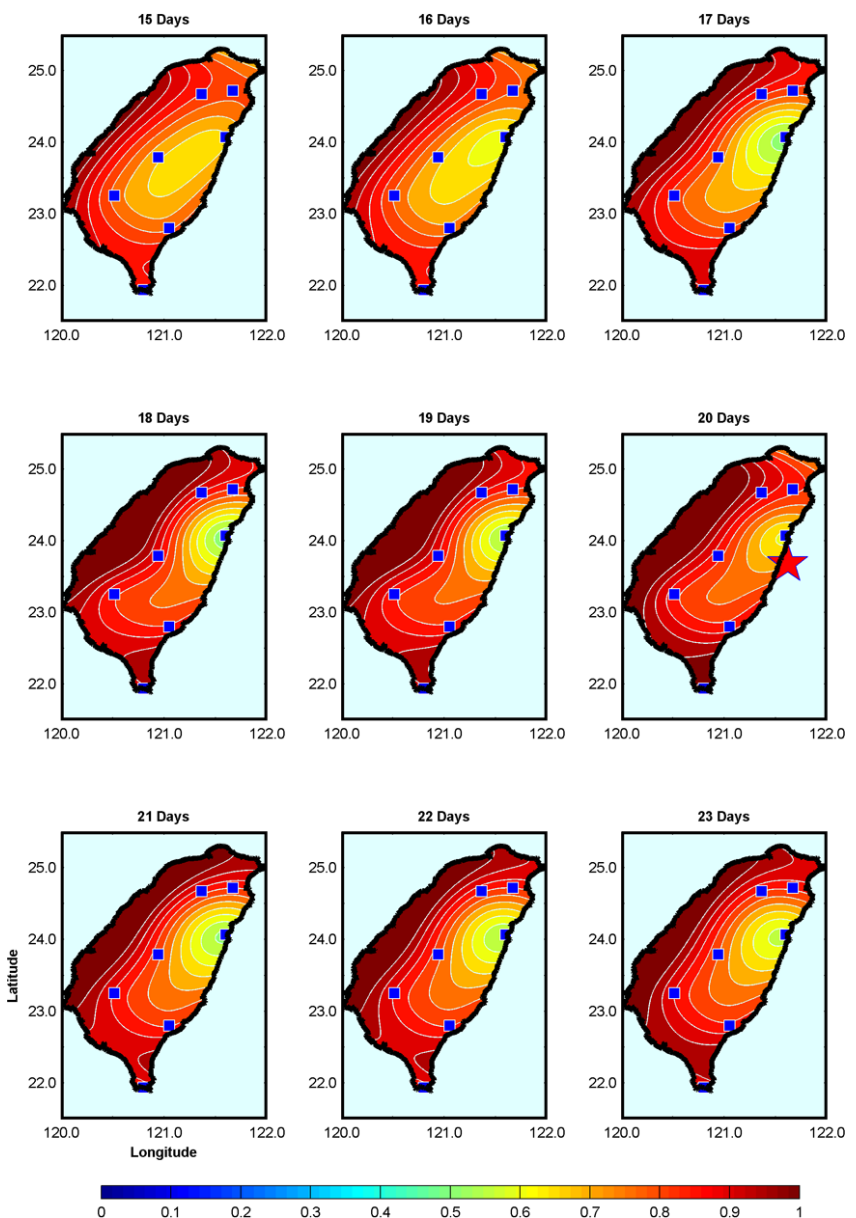

Fig. 5. A contour map of the cross correlation values from nighttime data during EQ1. Blue squares indicate locations of the geomagnetic stations in Taiwan. A red star represents the epicenter of EQ1. Color lines on Taiwan denote the cross correlation values.

relation at the 8 stations. It is clear to find that values of the cross correlation generally approach 1 , which suggests that variations of two processed amplitudes within the examined window are very similar, regardless of magnetic storms. This implies that changes of the cross correlation values and magnetic storms exhibit an independent relationship. Thus, if the cross correlation values can be related to earthquakes, these would be a good seismo-magnetic indicator of the partial influence of magnetic storms. It is interesting to find that the values of cross correlation sometimes decrease along with earthquakes, such as on about 30th day at the NC station and about 95th day at the TT station. When decreased values of the cross correlation are examined with earthquake catalog (Table 2), earthquake occurrence and anomalous stations (i.e. decreased values of the cross correlation) yield a good agreement in the time scale. To further clarify this relationship in the spatial domain, time-varied contour maps are constructed with the values of the cross correlation at the 7 stations located in Taiwan. Figure 5 shows the contour maps between 
15 September and 23 September, entirely covering EQ1. Relatively small values of the cross correlation were initially observed in central Taiwan, near the HL and SL stations. The values of the cross correlation promptly decreased and gradually increased 3 days before and after at the HL station, respectively, where located nearby is the epicenter of EQ1. This similar evolution (i.e. decreased values of the cross correlation near epicenters) is repeatedly observed during EQ2EQ9, except for EQ4, EQ5 and EQ9 (also see the Appendix) and applies about $67 \%(=6 / 9)$ accuracy in estimating time and location information in relation to earthquakes. Therefore, this method is very useful to remove effects of magnetic storms on studies of seismo-magnetic anomalies.

\section{Discussion and conclusion}

In terms of the Tohoku earthquake, the phenomena (i.e. decrease of the cross correlation values) that appeared about 5 days before this grave event are observed at 8 stations, which are located about $2500 \mathrm{~km}$ away from the epicenter. The values ( $\sim 0.6$; also see Fig. A6 in Appendix), which suggest seismo-magnetic anomalies, could be observed in Taiwan regions during the Tohoku earthquake, but they are almost even at all the studied stations (i.e. including the KM station located about $300 \mathrm{~km}$ away; also see Fig. 4). Thus, no obvious area with a relatively small value could be determined as an epicenter. When the time-varied values of the cross correlation are further reexamined, the even small values lie on Taiwan regions as well as the KM place, significantly appearing on 78th, 114th, 136th, 163rd and 178th days without earthquake occurrence. Thus, it is difficult to determine whether seismo-magnetic anomalies affected geomagnetic fields in Taiwan during the Tohoku earthquake or not. This confusing effect (i.e. the small cross correlation values in large-scale areas) could be caused by variations of the ionosphere and/or other unknown factors, limited within either $0.01-0.1 \mathrm{~Hz}$ or $0.001-0.01 \mathrm{~Hz}$. This effect would damage accuracy of determination of seismo-magnetic anomalies, but could be partial mitigated when the values at the KM station are simultaneously taken into account. Note that the KM station is located at an aseismicity zone. The consistent changes of the values between KM and the other 7 stations would not be considered as local effects associated with earthquakes.

Timings and/or locations of forthcoming earthquakes can be effectively estimated by using FFT (Fraser-Smith et al., 1990), the fractal method (Hayakawa et al., 1999), the flicker noise spectroscopy (Hayakawa and Timashev, 2006), the radiometric method (Kopytenko et al., 2001), and the principle component analysis (Hattori et al., 2004b) as well as anomalous daily variation ranges (Liu et al., 2006). Hattori (2004) summarized empirical observations from many major earthquakes, and found that the distance of the success detection for ULF emission waves is proportional to earth- quake magnitude. Thus, seismo-magnetic anomalies would be related to timings, location, and magnitude of forthcoming earthquakes. Although Chen et al. (2011b) reported that earthquake-related stress changes can be observed by using Global Positioning System, mechanisms of seismo-magnetic anomalies resulting from stress accumulation are not fully understood, despite extensive discussion in previous studies. Merzer and Klemperer (1997) and Yen et al. (2004) suggested that high conductivity and/or currents along faults are main causes of observed anomalies during earthquakes. Otherwise, Chen et al. $(2009 \mathrm{~b}, 2010)$ proposed a hybrid system and observed seismo-magnetic waves emitted from SMARTs (surface magnetic anomalous reference tips). In short, materials with high conductivity or susceptibility can be formed near epicenters, faults or SMARTs by any possible mechanism. On the other hand, these ULF emission waves could be observed within the epicentral distance of about $70-80 \mathrm{~km}$ for earthquakes with magnitude of about 6 (Hayakawa and Hattori 2004). Ohta et al. (2001, 2005, 2007) proposed that these emission waves would propagate in the Earth-ionosphere waveguide with small attenuation as $\mathrm{TM}_{0}$ (or TEM) mode over great distances (Bliokh et al., 1980). Long-range transmissions of the emission waves were also observed in Japan about $2000 \mathrm{~km}$ and $5500 \mathrm{~km}$ away from the epicenter of Chi-Chi $(M=7.6$ on 20 September 1999) (Ohta et al., 2001) and the Sumatra earthquake $(M=9.0$ on 26 December 2004) (Ohta et al., 2007), respectively.

In summary, magnetic storms could deeply affect variations of geomagnetic fields and disturb accuracy of detections of seismo-magnetic signals from amplitudes via FFT alone. We employed characteristics of magnetic storms, which enhance amplitude regardless of frequency, and computed the cross correlation values between the earthquakerelated $(0.01-0.1 \mathrm{~Hz})$ and relatively low $(0.001-0.01 \mathrm{~Hz})$ frequency bands to reduce influence caused by magnetic storms. The relatively small values of the cross correlation sometimes lie in wide areas to affect accuracy of detections of seismo-magnetic signals due to changes of the ionosphere and/or unknown factors and this phenomenon can be partially mitigated once other far away stations are taken into account, simultaneously. When the effects of magnetic storms and changes of the ionosphere disturbing wide areas are eliminated, the relatively small values are observed near epicenters a few days before and after $67 \%(=6 / 9)$ of earthquakes. 

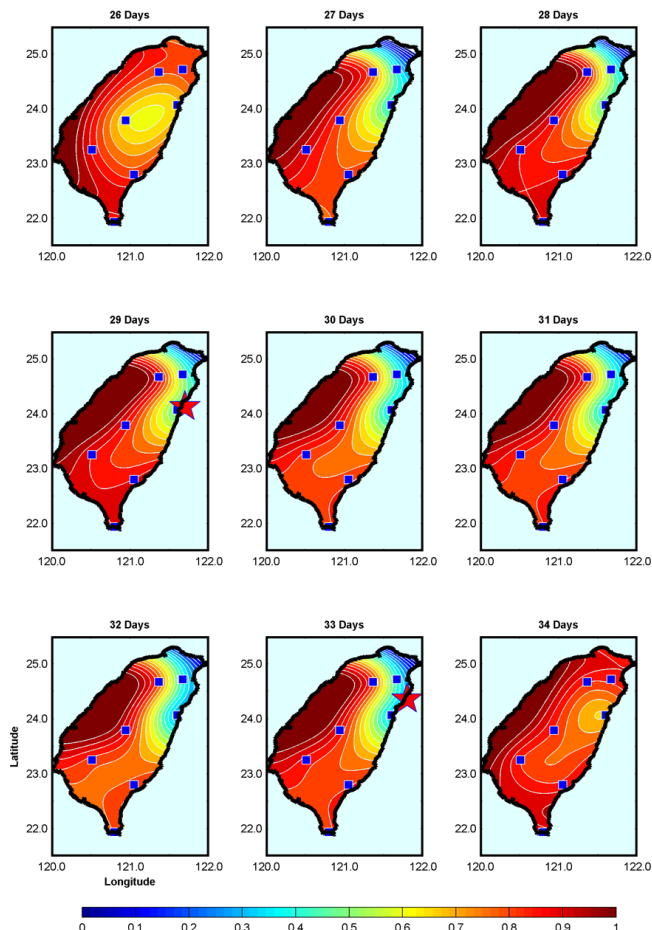

Fig. A1. A contour map of the cross correlation values from nighttime data during EQ2 and EQ3. Blue squares indicate locations of the geomagnetic stations in Taiwan. Red stars represent the epicenter of EQ2 and EQ3. Color lines on Taiwan denote the cross correlation values.
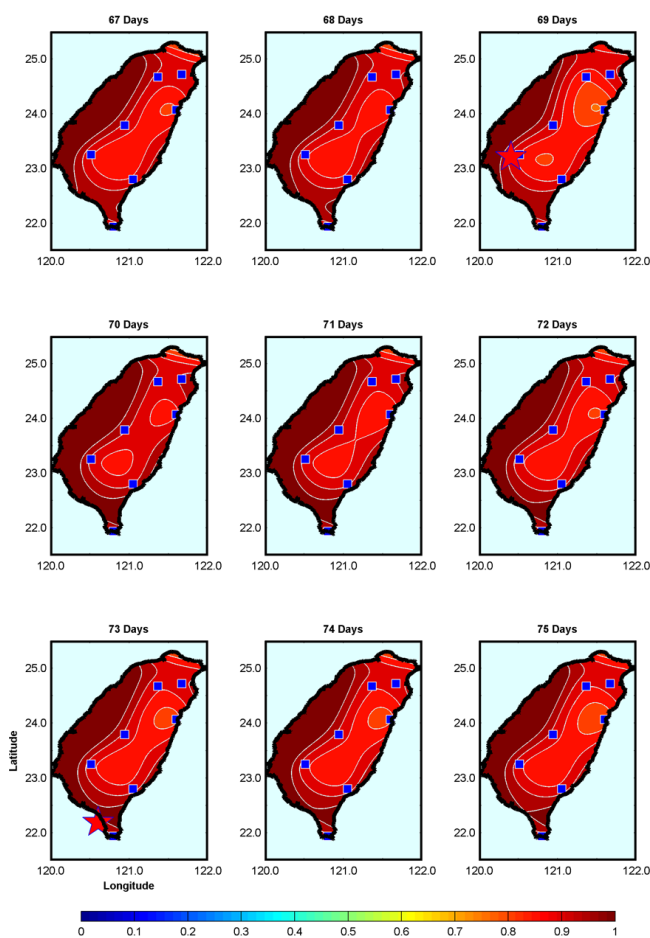

Fig. A2. A contour map of the cross correlation values from nighttime data during EQ4 and EQ5 (the red stars).
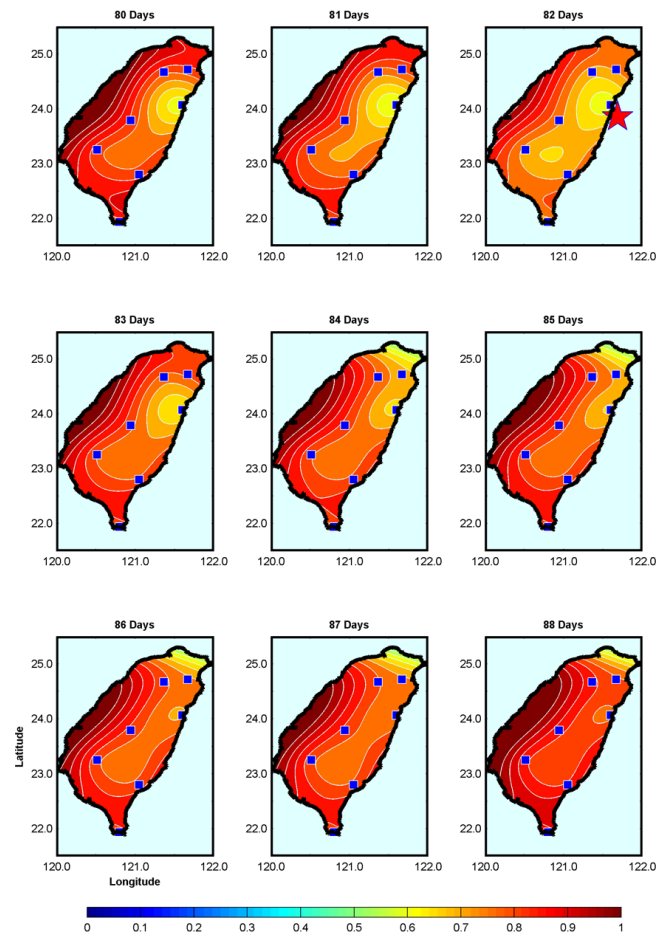

Fig. A3. A contour map of the cross correlation values from nighttime data during EQ6 (the red star).
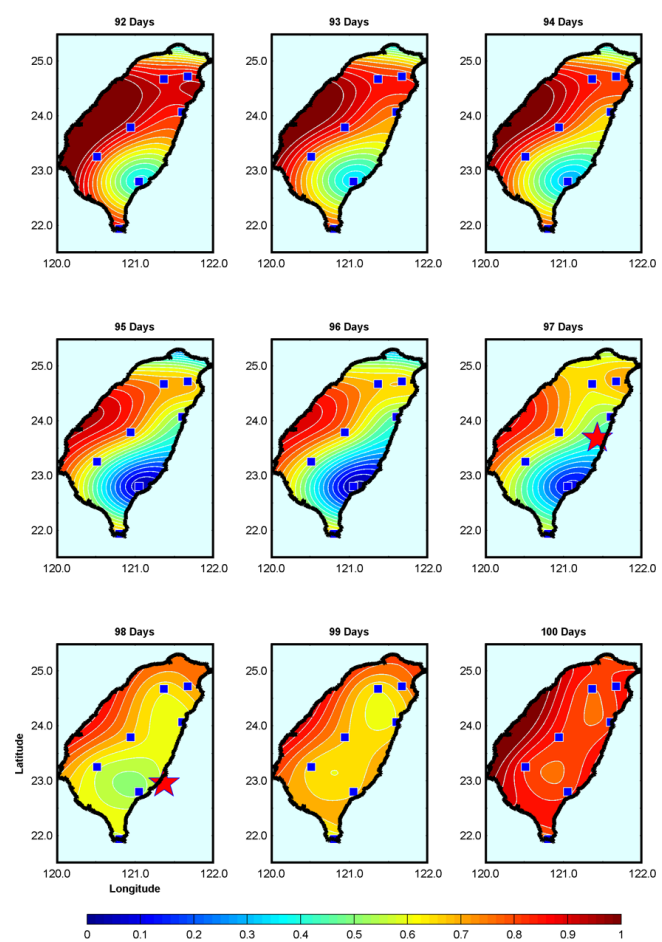

Fig. A4. A contour map of the cross correlation values from nighttime data during EQ7 and EQ8 (the red stars). 

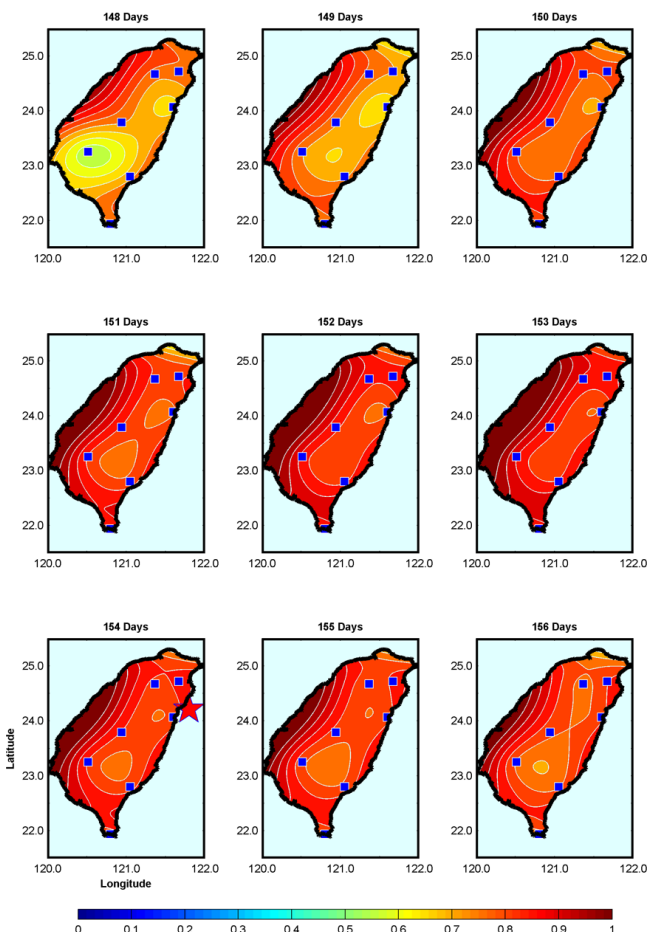

Fig. A5. A contour map of the cross correlation values from nighttime data during EQ10 (the red star).
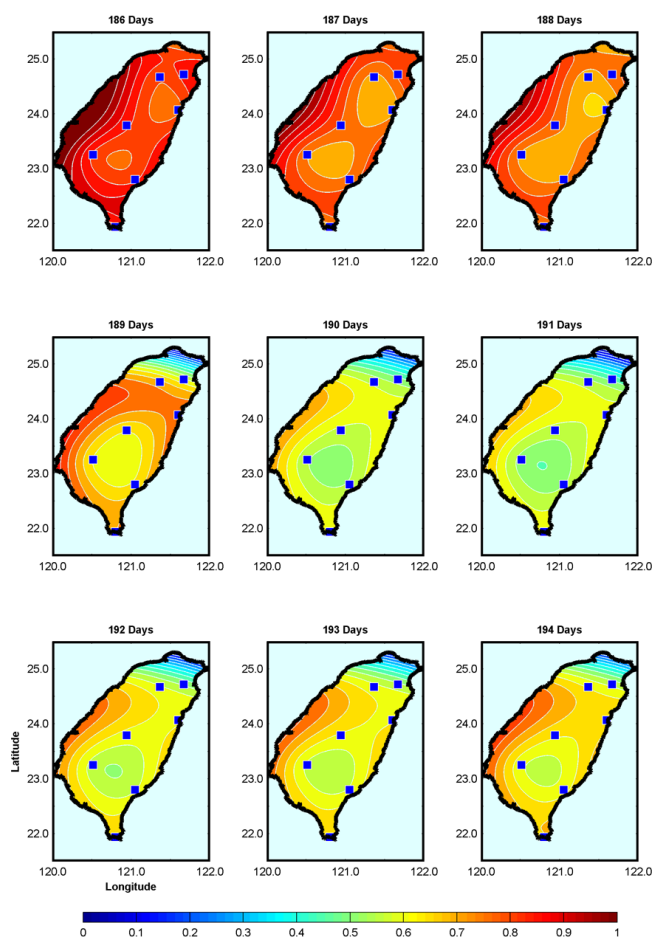

Fig. A6. A contour map of the cross correlation values from nighttime data during the Tohoku earthquake (on 192nd day).
Acknowledgements. The authors appreciate the valuable comments raised by the reviewers to greatly improve the manuscript and wish to express their appreciation to the Central Weather Bureau for providing high quality geomagnetic data. The National Science Council of the Republic of China financially supports this research under Contracts NSC 100-2116-M-001-027-MY3.

Edited by: M. E. Contadakis

Reviewed by: two anonymous referees

\section{References}

Bernardi, A., Fraser-Smith, A. C., McGill, P. R., and Villard Jr., O. G.: ULF magnetic field measurements near the epicenter of the Ms 7.1 Loma Prieta earthquake, Phys. Earth Planet. Int., 68, 45-63, 1991.

Bliokh, P. V., Nickolaenko, A. P., Filippov, and Yu. F.: Schumann Resonances in the Earth-ionosphere Cavity, Peter Peregrinus Ltd., Stevenage, UK, 1980.

Chapman, S. and Bartels, J.: Geomagnetism, Vol. I: Geomagnetic and Related Phenomena, Vol. II: Analysis of Data and Physical Theories, Oxford Univ. Press, Oxford, London, 1049 pp., 1940.

Chapman, S. and Miller, J. C. P.: The statistical determination of lunar daily variations in geomagnetic and meteorological elements, Monthly Notices Roy. Astr. Soc. Geophys. Suppl., 4, 649-669, doi:10.1111/j.1365-246X.1940.tb02923.x, 1940.

Chen, C. H., Liu, J. Y., Yen, H. Y., Zeng, X., and Yeh, Y. H.: Geomagnetic total field and occurrences of earthquakes in Taiwan, Terr. Atmo. Ocean. Sci., 15, 361-37, 2004.

Chen, C. H., Lin, C. R., Chao, H. L., Yen, H. Y., Liu, J. Y.m and Yeh, Y. H.: Evaluation of the Applicability of Chapman-Miller Method on Variation of the Geomagnetic Total Intensity Field in Taiwan from 1988 to 2007, Terr. Atmo. Ocean. Sci., 20, 799806, doi:10.3319/TAO.2009.02.03.01(T), 2009a.

Chen, C. H., Liu, J. Y., Yang, W. H., Yen, H. Y., Hattori, K., Lin, C. R., and Yeh, Y. H.: SMART analysis of geomagnetic data observed in Taiwan, Phy. Chem. Earth., 34, 350-359, doi:10.1016/j.pce.2008.09.002, 2009b.

Chen, C. H., Liu, J. Y., Lin, P. Y., Liang, W. T., Yen, H. Y., Hattori, K., and Zeng, X.: Pre-seismic Geomagnetic Anomaly and Earthquake Location, Tectonophysics, 489, 240 247, dio:10.1016/j.tecto.2010.04.018, 2010.

Chen, C. H., Wen, S., Liu, J. Y., Yeh, T. K., Wang, C. H., Yen, H. Y., Hattori, K., and Lin, C. R.: Seismomagnetic Signal Comparison using the Morlet Wavelet Method, Disaster Adv., 4, 53-60, 2011 a.

Chen, C. H., Yeh, T. K., Liu, J. Y., Wang, C. H., Wen, S., Yen, H. Y., and Chang, S. H.: Surface Deformation and Seismic Rebound: implications and applications, Surv. Geophys., 32, 291313, doi:10.1007/s10712-011-9117-3, 2011b.

Fraser-Smith, A. C., Bernardi, A., McGill, P. R., Ladd, M. E., Helliwell, R. A., and Villard Jr., O. G.: Low-frequency magnetic field measurements near the epicenter of the Ms 7.1 Loma Prieta earthquake, Geophys. Res. Lett., 17, 1465-1468, 1990.

Gotoh, K., Akinaga, Y., Hayakawa M., and Hattori, K.: Principal component analysis of ULF geomagnetic data for Izu islands earthquakes in July 2000, J. Atmos. Electr., 22, 1-12, 2002.

Hattori, K., Akinaga, Y., Hayakawa, M., Yumoto, K., Nagao, T., and Uyeda, S.: ULF magnetic anomaly preceding 
the 1997 Kagoshima Earthquakes, in: Seismo Electromagnetics: Lithosphere-Atmosphere-Ionosphere coupling, edited by: Hayakawa, M. and Molchanov, O. A., Terra Scientific. Pub. Comp, Tokyo, 477 pp., 2002.

Hattori, K.: ULF geomagnetic changes associated with large earthquakes, Terr. Atmos. Ocean. Sci., 15, 329-360, 2004.

Hattori, K., Takahashi, I., Yoshino, C., Isezaki, N., Iwasaki, H., Harada, M., Kawabata, K., Kopytenko, E., Kopytenko, Y., Maltsev, P., Korepanov, V., Molchanov, O., Hayakawa, M., Noda, Y., Nagao, T., and Uyeda, S.: ULF geomagnetic field measurements in Japan and some recent results associated with Iwateken Nairiku Hokubu Earthquake in 1998, Phys. Chem. Earth., 29, 481-494, 2004a.

Hattori, K., Serita, A, Gotoh, K., Yoshino, C., Harada, M., Isezaki, N., and Hayakawa, M.: ULF geomagnetic anomaly associated with $2000 \mathrm{Izu}$ islands earthquake swarm, Japan, Phys. Chem. Earth., 29, 425-435, 2004b.

Hayakawa, M. and Fujinawa, Y.: Electromagnetic Phenomena Related to Earthquake Prediction, Terra Scientific, Pub. Comp., Tokyo, 677 pp., 1994.

Hayakawa, M., Kawate, R., Molchanov, O. A., and Yumoto, K.: Results of ultra-low-frequency magnetic field measurements during the Guam earthquake of 8 August 1993, Geophys. Res. Lett., 23, 241-244, 1996.

Hayakawa, M.: Atmospheric and Ionospheric Electromagnetic Phenomena Associated with Earthquakes, Terra Scientific, Pub. Comp., Tokyo, 996 pp., 1999.

Hayakawa, M., Itoh, T., and Smirnova, N.: Fractal analysis of ULF geomagnetic data associated with the Guam earthquake on August 8, 1993, Geophys. Res. Lett., 26, 2797-2800, 1999.

Hayakawa, M., Itoh, T., Hattori, K., and Yumoto, K.: ULF electromagnetic precursors for an earthquake at Biak, Indonesia on February 17, 1996, Geophys. Res. Lett., 27, 1531-1534, 2000.

Hayakawa, M. and Molchanov, O. A.: Seismo Electromagnetics: Lithosphere-Atmosphere-Ionosphere coupling, Terra Scientific, Pub. Comp., Tokyo, 477 pp., 2002.

Hayakawa, M. and Hattori, K.: Ultra-low-frequency electromagnetic emissions associated with earthquakes, IEEJ Trans. FM, 124, 1101-1108, 2004.

Hayakawa, M. and Timashev, S. F.: An attempt to find precursors in the ULF geomagnetic data by means of flicker noise spectroscopy, Nonlin. Processes Geophys., 13, 255-263, doi:10.5194/npg-13-255-2006, 2006.

Ho, C. S.: An Introduction to the Geology of Taiwan, Central Geological Survey, The Ministry of Economic Affairs, Taipei, 2nd Edn., 192 pp., 1988.

Karakelian, D., Klemperer, S. L., Fraser-Smith, A .C., and Thompson, G. A.: Ultra-low frequency electromagnetic measurements associated with the $1998 \mathrm{Mw}$ 5.1 San Juan Bautista, California earthquake and implications for mechanisms of electromagnetic earthquake precursors, Tectonophysics, 359, 65-79, 2002.

Kawate, R., Molchanov, O. A., and Hayakawa, M.: Ultra-lowfrequency magnetic fields during the Guam earthquake of $8 \mathrm{Au}-$ gust 1993 and their interpretation, Phys. Earth Planet. Int., 105, 229-238, 1998.
Kopytenko, Y. A., Matishvili, T. G., Voronov, P. M., Kopytenko, E. A., and Molchanov, O. A.: Detection of ultra-low-frequency emissions connected with the Spitak earthquake and its aftershock activity, based on geomagnetic pulsations data at Dusheti and Vardzia observatories, Phys. Earth Planet. Int., 77, 85-95, 1993.

Kopytenko, Y. A., Ismaguilov, V. S., Hayakawa, M., Smirnova, N., Troyan, V., and Peterson, T.: Investigation of the ULF electromagnetic phenomena related to earthquakes: contemporary achievements and perspectives, Ann. Geofis., 44, 325-334, 2001.

Liu, J. Y., Chen, C. H., Chen, Y. I., Yen, H. Y., Hattori, K., and Yumoto, K.: Seismo-geomagnetic anomalies and $\mathrm{M} \geq 5.0$ earthquakes observed in Taiwan during 1988-2001, Phys. Chem. Earth., 30, 215-222, 2006.

Merzer, M. and Klemperer, S. L.: Modeling low-frequency magnetic-field precursor to the Loma Prieta earthquake with a precursory increase in fulat-zone conductivity, Pure Appl. Geophys., 150, 217-248, 1997.

Molchanov, O. A., Kopytenko, Y. A., Voronov, R. M., Kopytenko, E. A., Matiashvili, T. G., Fraser-Smith, A. C., and Bernardi, A.: Results of ULF magnetic field measurements near the epicenters of the Spitak $(\mathrm{Ms}=6.9)$ and Loma Prieta $(\mathrm{Ms}=7.1)$ earthquakes: Comparative analysis, Geophys. Res. Lett., 19, 14951498, 1992.

Molchanov, O. A. and Hayakawa, M.: Seismo Electromagnetics and Related Phenomena: History and latest results, Terra Scientific, Pub. Comp., Tokyo, 189 pp., 2008.

Ohta, K., Umeda, K., Watanabe, N., and Hayakawa, M.: ULF/ELF emissions observed in Japan, possibly associated with the ChiChi earthquake in Taiwan, Nat. Hazards Earth Syst. Sci., 1, 3742, doi:10.5194/nhess-1-37-2001, 2001.

Ohta, K., Watanabe, N. and Hayakawa, M.: The observation of ULF emissions at Nakatsugawa in possible association with the 2004 Mid Niigata Prefecture earthquake, Earth Planets Space, 57, 1003-1008, 2005.

Ohta, K., Watanabe, N., and Hayakawa, M.: The observation of ultra-low frequency emissions at Nakatsugawa, Japan, in possible association with the Sumatra, Indonesia, earthquake, Int. J. Remote Sens., 28, 3121-3131, 2007.

Rozhnoi, A., Solovieva, M., Molchanov, O., Schwingenschuh, K., Boudjada, M., Biagi, P. F., Maggipinto, T., Castellana, L., Ermini, A., and Hayakawa, M.: Anomalies in VLF radio signals prior the Abruzzo earthquake $(M=6.3)$ on 6 April 2009, Nat. Hazards Earth Syst. Sci., 9, 1727-1732, doi:10.5194/nhess-91727-2009, 2009.

Yen, H. Y., Chen, C. H., Yeh, Y. H., Liu, J. Y., Lin, C. R., and Tasi, Y. B.: Geomagnetic fluctuations during the 1999 Chi-Chi earthquake in Taiwan, Earth Planet. Space, 56, 39-45, 2004.

Yen, H. Y., Chen, C. H., Hsieh, H. H., Lin, C. R., Yeh, Y. H., Tsai, Y. B., Liu, J. Y., Yu, G. K., and Chen, Y. R.: Magnetic Survey of Taiwan and Its Preliminary Interpretations, Terr. Atmos. Ocean. Sci., 20, 309-314, doi:10.3319/TAO.2008.04.08.01(T), 2009. 